Génét. Sél. Evol., 1987, 19 (3), 289-296

\title{
Polymorphisms of inversions and Adh alleles in eye colour mutant experimental populations of Drosophila melanogaster
}

\author{
Carmen NÁJERA and J.L. MÉNSUA \\ Departamento de Genética, Facultad de Ciencias Biológicas, \\ Universidad de Valencia, Dr. Moliner, 50, Burjassot, Valencia, Spain
}

\begin{abstract}
Summary
From laboratory populations (wild/se ; wild/sf ; wild/cd and wild/multichromosomal) originated from strains coming from a cellar anci using two culture media, one standard and the other supplemented with 10 p. 100 ethanol, strong heterosis was observed. It has been confirmed that this heterosis cannot be explained by the maintenance of inversions in heterozygosis and that there is a fixation of the $F$ allele in all the populations supplemented with ethanol while all the populations maintained in the standard culture medium remain polymorphic.
\end{abstract}

Key words : D. melanogaster, inversion, Adh, eye colour mutant, ethanol.

\section{Résumé}

Polymorphismes des inversions et du locus Adh dans des populations expérimentales de Drosophila melanogaster mutantes pour la couleur des yeux

A partir de populations de laboratoire (sauvage/se ; sauvage/sf ; sauvage/cd ; et sauvage/multichromosomique) provenant de souches capturées dans une cave à vin et entretenues sur deux milieux différents, l'un standard et l'autre avec éthanol à $10 \mathrm{p}$. 100 , on a détecté une hétérosis. On a confirmé que cette hétérosis ne pouvait pas être expliquée par le maintien des inversions en hétérozygotie et qu'il y avait une fixation de l'allèle $F$ dans toutes les populations élevées sur le milieu avec éthanol alors que toutes les populations élevées sur le milieu standard restaient polymorphiques.

Mots clés: D. melanogaster, inversion, Adh, mutant de couleur des yeux, éthanol.

\section{Introduction}

The problem of genetic variability and its maintenance in natural populations has been studied for chromosomal and enzymatic polymorphism and, most recently, in respect to DNA sequences in Drosophila.

At the chromosomal level, the classic works of DoBzhansky's group (1951) about the adaptive value of inversions have given numerous proofs in favour of adaptive 
variability. The environmental conditions which determine differences in the distribution of species could also determine changes in the frequency of inversions. For example, studies of the distribution of the ecological niches of $D$. melanogaster and D. simulans show that the former, more tolerant to ethanol, is distributed both inside and outside cellars (McKenzie \& PARSOns, 1972-1974) ; in the same way D. melanogaster is polymorphic for chromosome arrangements and $D$. simulans is monomorphic.

Nevertheless, at enzymatic level, evidence which proves directly that polymorphisms are subject to selection is rare, with some exceptions like the Adh polymorphism in Drosophila (Gibson, 1970 ; Cavener \& ClegG, 1978, 1981 ; VAN Herrewege \& DAvid, 1984).

NÁJERA (1985), studying the changes in gene frequency of 4 eye colour mutants or $D$. melanogaster from a cellar, in competition with their wild allele from the same habitat, observed that the 4 mutants reached different gene frequencies at equilibrium and that the frequency of heterozygotes for each mutant was significantly higher than expected. NÁJERA \& MÉNSUA (1985), studying viability of the same five strains at different ethanol concentrations (between 0 and $20 \mathrm{p}$. 100) and at 2 levels of competition, observed that in all the experimental conditions tested the mean viability of heterozygotes $(+/ \mathrm{m})$ was higher than that of both homozygotes $(+/+; \mathrm{m} / \mathrm{m})$.

A study of the frequency of inversions in these populations was proposed to check whether they could explain the heterozygote advantage found in all populations, together with a study of the frequency of Adh alleles, due to their relation to the alcohol metabolic pathway, to discover whether the gene frequency of the mutant in the populations supplemented with ethanol was due to this locus.

\section{Material and methods}

From wild females of $D$. melanogaster captured in a cellar in Requena (Valencia, Spain), 5 isofemale strains were established, 4 of them were eye colour mutants : se, sf, cd and multichromosomal (cd, cn,?) and the other (wild strain) did not segregate any mutant. The 5 strains were used to establish laboratory populations by crossing 50 wild individuals with 50 of each one of the mutants using 2 nutritive media : one standard and the other supplemented with 10 p.100 ethanol. In both media the evolution of the gene frequency of the mutants was followed during 42 generations and an equilibrium frequency of 0.32 (se), 0.28-0.22 (sf), 0.19 (cd) and 0.09 (multichromosomal) was reached with differences between the 2 media only in the sf mutant, which had a higher frequency in the ethanol medium (NÁJERA, 1985).

An analysis of inversions in the 8 populations described as well as in the 5 strains (wild and four mutants) which gave rise to these populations was made.

In the same way a study was made of the frequency of the $F$ (fast) and $S$ (slow) Adh alleles in the same strains and populations.

The inversions were analyzed through crosses with the " rucuca " strain (LiNDSLEY \& GRELL, 1972), homozygous for standard-sequence chromosomes. Ten crosses per population and per strain were made, analyzing seven third instar larvae from the offspring; thus, the probability of observing the 2 male chromosomes was 0.99 . The method used was the conventional one for the extraction of the giant salivary glands : 
stain (acetic-orcein- 80 p. 100 , lactic acid-20 p. 100) and posterior squash. The cytological nomenclature followed that of LINDSLEY \& GRELL (1972) and the break points of the inversions were identified by reference to the standard map of BRIDGES (1935).

Frequency of Adh alleles was determined by starch gel electrophoresis in 10 p. 100 Tris-ClH $0.05 \mathrm{M} \mathrm{pH} 8.6$ making slots in the gel where papers impregnated with homogenized flies were deposited. The electrophoresis was left running during 5 hours, marking the front with bromophenol blue, and was then incubated for 3 hours at $37{ }^{\circ} \mathrm{C}$ with a reactive mixture made by combining a) $45 \mathrm{ml}$ Tris- $\mathrm{ClH} 0.05 \mathrm{M}$ and $0.36 \mathrm{~g}$ agar-agar and b) $0.04 \mathrm{~g} \mathrm{NAD}^{+}, 0.02 \mathrm{~g} \mathrm{MTT,} 0.18 \mathrm{~g}$ EDTA, $4 \mathrm{mg}$ PMS and $2 \mathrm{ml}$ isopropanol. After this time the reading was made. Stock references with known Adh phenotypes were used as standards.

\section{Results and discussion}

The inversions found, and their frequency, are shown in table 1 , following the classification of MetTler et al. (1977). Three of the inversions found belong to the common cosmopolitan category. The $\operatorname{In}(3 R) 87 C-93 D$ has not been described previously.

TABLE 1

Types and frequencies of inversions in the strains and the populations.

\begin{tabular}{|c|c|c|c|c|c|c|}
\hline Strains & \multicolumn{4}{|c|}{$\begin{array}{c}\text { Number } \\
\text { of chromosomes } \\
\text { analyzed }\end{array}$} & \multicolumn{2}{|c|}{ Types and frequencies of inversions } \\
\hline & \multicolumn{2}{|c|}{2} & \multicolumn{2}{|c|}{3} & \\
\hline 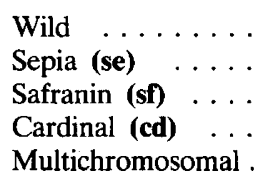 & & & & $\begin{array}{l}0 \\
0 \\
0 \\
0 \\
0\end{array}$ & $\begin{array}{r}\operatorname{In}(2 R) \\
\ln (3 R) 87 C \\
\operatorname{In}(2 L) t\end{array}$ & $\begin{array}{l}-5 \% \\
D^{*}-30 \% \\
100 \%\end{array}$ \\
\hline \multirow[t]{3}{*}{ Populations } & \multicolumn{4}{|c|}{$\begin{array}{c}\text { Number } \\
\text { of chromosomes } \\
\text { analyzed }\end{array}$} & \multicolumn{2}{|c|}{ Types and frequencies of inversions } \\
\hline & \multicolumn{2}{|c|}{$\begin{array}{l}\text { With } \\
\text { alcohol }\end{array}$} & \multicolumn{2}{|c|}{$\begin{array}{l}\text { Without } \\
\text { alcohol }\end{array}$} & $\begin{array}{l}\text { With } \\
\text { alcohol }\end{array}$ & $\begin{array}{l}\text { Without } \\
\text { alcohol }\end{array}$ \\
\hline & 2 & 3 & 2 & 3 & & \\
\hline 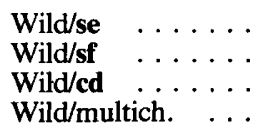 & $\begin{array}{l}\frac{-}{20} \\
\frac{-}{20}\end{array}$ & $\begin{array}{l}20 \\
20 \\
20\end{array}$ & $\frac{\overline{20}}{\overline{20}}$ & $\begin{array}{l}\frac{20}{20} \\
20\end{array}$ & $\begin{array}{c}\operatorname{In}(3 R) 87 C-93 D^{*}-5 \% \\
\operatorname{In}(3 R) \bar{P}-5 \% \\
\ln (2 R) N S-10 \%\end{array}$ & $\begin{array}{c}\operatorname{In}(2 R) \bar{N} S-5 \% \\
\operatorname{In}(3 R) P-5 \% \\
\operatorname{In}(2 R) N S-15 \%\end{array}$ \\
\hline
\end{tabular}

* New chromosomal inversion. 
The break-points are located in the regions $87 \mathrm{C}$ and 93D (fig. 1). The double appearance of this inversion (in a strain and in a population coming from 2 other strains) in individuals from the same cellar, makes it very difficult to explain its appearance by hybrid dysgenesis. In this same cellar population, GonZÁLEZ (1985) found another inversion not previously described. Other data (PREvOSTI, personal communication) indicate a certain number of endemic inversions in cellar populations.

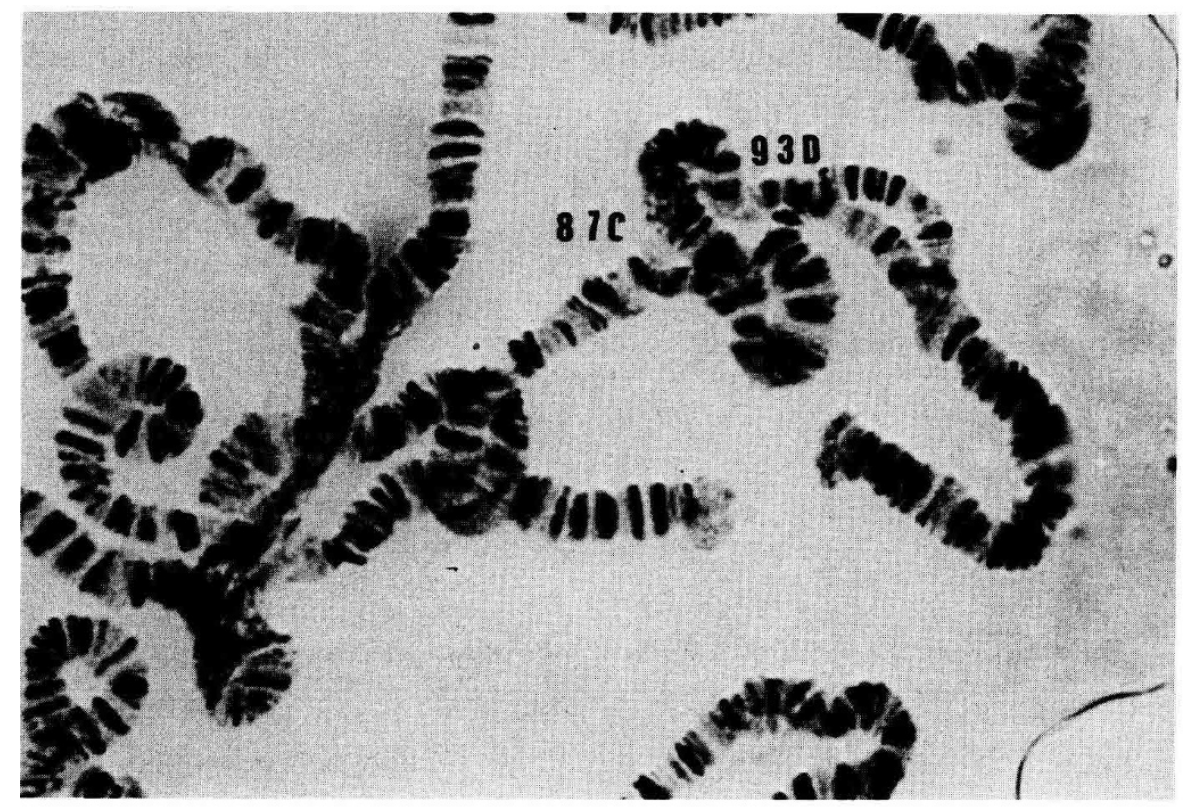

Fig. 1

New chromosomal inversion with break points in the regions $87 C$ and $93 D$.

No mutations are included inside the inversions. Only cd is located near one break-point of the $\operatorname{In}(3 R) P$ but the frequency of this inversion is very low in both media (5 p. 100). In the multichromosomal strain, the $\operatorname{In}(2 L) t$ was found in the ten individuals analyzed, which could explain a certain degree of association between the mutations included in the strain and the inversion. Nevertheless, of the 2 mutations which the strain has with certainty, ed is located in chromosome 3 and $\mathbf{c n}$ is in the $2 \mathrm{R}$ arm, so the only possibility would be that the other mutation which it is supposed that this strain has, is included in the inversion. In the wild/multichromosomal population which originated from this strain the inversion was not detected, but due to the low frequency of mutants at the time of analysis this association cannot be discarded.

The frequency of inversions found in the heterozygous state in these populations is very low in all cases (between 0 and $15 \mathrm{p} .100$ ) so it is difficult to believe that this could explain the heterozygote advantage found in the populations and their higher viability. 
However, we cannot reject the possibility that other unrecognizable factors can cause the changes in visible frequencies in these laboratory populations. It is possible that the experimental techniques could produce linkage disequilibrium between the eye colour locus and other loci which are themselves likely subjected to selection. For example, JoNES \& YAMAZAKI (1974) proved that the changes in allozyme frequency in laboratory populations founded with a relatively small sample of a natural population or subjected to many generations of inbreeding are not necessarily due to the action of selection at the single locus under consideration.

The results of the population analysis regarding Adh polymorphism are shown in table 2. All the populations maintained in the standard culture medium showed polymorphism while the populations maintained in $10 \mathrm{p}$. 100 ethanol all appeared homozygous for the $F$ allele. As regards the strains, the wild strain and three of the four mutants (se, sf, cd) are homozygous for the $F$ allele and the multichromosomal are homozygous for the $S$. Thus, contrasting with the stable polymorphism which exists in both media for the eye colour loci, the Adh locus is only polymorphic in normal medium, while in alcohol medium there is always monomorphism for the $F$ allele.

TABLE 2

Frequencies of Adh alleles in the strains and the populations.

\begin{tabular}{|c|c|c|c|c|}
\hline Strains & Number of individuals analyzed & $\% F F$ & $\% F S$ & $\% S S$ \\
\hline 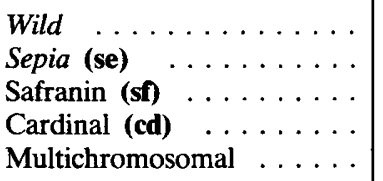 & $\begin{array}{r}84 \\
96 \\
150 \\
95 \\
150\end{array}$ & $\begin{array}{l}100 \\
100 \\
100 \\
100 \\
-\end{array}$ & $\begin{array}{l}- \\
- \\
- \\
-\end{array}$ & $\begin{array}{l}- \\
- \\
- \\
- \\
100\end{array}$ \\
\hline Populations & Number of individuals analyzed & $\% \mathrm{FF}$ & $\%$ FS & $\%$ SS \\
\hline $\begin{array}{l}\text { Wild/se with alcohol } \ldots \ldots \\
\text { Wild/se without alcohol } \ldots \\
\text { Wild/sf with alcohol } \ldots \\
\text { Wild/sf without alcohol } \ldots \\
\text { Wild/cd with alcohol } \ldots \\
\text { Wild/cd without alcohol } \ldots \\
\text { Wild/multich. with alcohol } \\
\text { Wild/multich. without alcohol }\end{array}$ & $\begin{array}{r}106 \\
89 \\
86 \\
80 \\
85 \\
78 \\
141 \\
96\end{array}$ & $\begin{array}{r}100 \\
45 \\
100 \\
40 \\
100 \\
32 \\
100 \\
19\end{array}$ & $\begin{array}{l}- \\
40 \\
- \\
47 \\
- \\
44 \\
- \\
43\end{array}$ & $\begin{array}{l}\overline{15} \\
\overline{13} \\
\overline{24} \\
- \\
-38\end{array}$ \\
\hline
\end{tabular}

Different authors (Morgan, 1975 ; VAN Delden et al., 1978 ; Bijlsma-Meeles, 1979), in experiments to study competition between larvae in food supplemented with different alcohols, found an advantage in the viability of the $F F$ genotype over the $S S$. The multichromosomal strain, the only one with an $S S$ genotype in the present work, 
has a lower viability compared with the other mutant strains with an $F F$ genotype, and this difference in viability increases with the increase in alcohol concentration (NÁJERA \& MénsuA, 1985).

Although the initial genetic constitution of the strains is not known, it seems possible that at least the wild strain, which is the origin of all the populations, was initially polymorphic, and that in the laboratory, it changed to monomorphic through the loss of the $S$ allele.

Only in the wild/sf populations is there a significant difference between the gene frequency reached by the mutant in a standard medium $(0.217$ in one replicate and 0.220 in the other) and in an alcohol medium (0.283 in one replicate and 0.278 in the other). This difference could be explained by a linkage disequilibrium between sf (2-71.5) and the $F$ allele (2-50.1), due to the $F$ allele fixation in the alcohol medium.

Studying the evolution of the gene frequency for the Adh locus in food supplemented with ethanol, many authors (GiBSON, 1970 ; BIJLSMA-MeEles \& VAN DeLDEN, 1974 ; Morgan, 1975 ; OAKeshott, 1976 ; Barnes \& Birley, 1978 ; Cavener \& Clegg, 1978, 1981 ; VAN HERREWEge \& DAVID, 1984) have found a rapid increase of the $F$ allele and even its fixation in most cases. Nevertheless, other studies (OAKESHOTT, 1979 ; OAKESHOTT \& GiBson, 1981) have obtained different results. In the populations supplemented with alcohol of the present work, there is a clear directional change due to selection, comparable to the previous works cited. This fact leads to the fixation of the $F$ allele and loss of the $S$ even in the population coming from a strain (multichromosomal) which has evolved towards a homozygous state for $S$ allele. It seems clear then that in these populations ethanol is a strong selective factor in favour of the $F$ allele. This contrasts drastically with the polymorphism existing in the populations maintained in the standard culture medium, which are in equilibrium and without an excess of either homozygotes or heterozygotes in any of them.

In relation with the Adh locus a linkage disequilibrium between the $\operatorname{In}(2 L) t$ and the $S$ allele has been found (Mukai et al., 1971 ; Voelker et al., 1978 ; AGUAdE \& SERRA, 1980 ; INOUE et al., 1984). The majority of these authors consider that this linkage is due to the founder effect and it is not a proof that appreciable selection pressure is exerted on individual isozyme loci.

In the multichromosomal strain the $\operatorname{In}(2 L) t$ and the $S$ allele of the Adh are both fixed, possibly due to a founder effect, although it is possible that the mentioned constitutions were fixed in the strain by genetic drift. Alternatively, the homozygous state for the $\operatorname{In}(2 L) t$ could explain the fixation of the $S$ allele, since it is the only strain in which this occurs, or, on the contrary, the fixation in the laboratory of the $S$ allele could have carried with it the fixation of the inversion.

Some authors (INOUE, 1979 ; INOUE et al., 1984) find that when natural populations are transferred to laboratory cages and maintained for a long time, they lose the chromosomal polymorphism but retain stable enzyme polymorphism. In the wild/multichromosomal population in a normal medium, the presence of the $\operatorname{In}(2 L) t$ was not detected. However, this does not signify the loss of linkage disequilibrium since the genotype of the 10 males analyzed for inversions, in respect of the Adh locus, was not known.

It can be concluded that the frequency of inversions in the heterozygous state is low in these populations, and that there is a fixation of the $F$ allele in all the populations supplemented with ethanol while all the populations maintained in a standard culture 
medium remain polymorphic. This fixation of the $F$ allele could explain the higher equilibrium frequency of the sf mutant in the alcohol population.

The appearance of an inversion not previously described, in 2 strains from the same cellar, indicates a possible endemism in this habitat.

Received July 28, 1986.

Accepted January 20, 1987.

\section{Acknowledgements}

We thank Dra DE Frutos for her assistance in the analysis of inversions.

\section{References}

Aguade M., Serra L., 1980. Spanish cellar population of Drosophila melanogaster. I. Study of variability at three different levels : quantitative, chromosomal and molecular. Acta Biol. Jugosl. Serv. Genet., 12, 111-120.

BARNES B.W., BIRLEy A.J., 1978. Genetical variation for enzyme activity in a population of D. melanogaster. IV. Analysis of Adh activity in chromosome substitution lines. Heredity, 40, 51-57.

BiJlsma-Meeles E., 1979. Viability in D. melanogaster in relation to age and Adh activity of eggs transferred to ethanol food. Heredity, 42, 79-89.

Bijlsma-Meeles E., Van Delden W., 1974. Intra and interpopulation selection concerning the Adh locus in D. melanogaster. Nature, 247, 369-371.

BRIDGES C.B., 1935. Salivary chromosome maps with a key to the banding of the chromosomes of Drosophila melanogaster. J. Hered., 26, 60-64.

Cavener D.R., Clegg M.T., 1978. Dynamics of correlated genetic systems. IV. Multilocus effects of ethanol stress environments. Genetics, 90, 629-644.

Cavener D.R., Clegg M.T., 1981. Multigenic response to ethanol in D. melanogaster. Evolution, 35, $1-10$.

Dobzhansky T., 1951, Genetics and the Origin of Species. 446 p., Columbia University Press, New York.

Gibson J.B., 1970. Enzyme flexibility in Drosophila melanogaster. Nature, 227, 959-960.

GONZALEZ A., 1985. Estudio de la estructura genetica de dos poblaciones naturales de D. melanogaster respecto a genes que afectan a la viabilidad. Tesis Doctoral, Universidad de Valencia.

Inoue Y., 1979. The fate of polymorphic inversions of Drosophila melanogaster transferred to laboratory conditions. Jpn. J. Genet., 54, 83-96.

Inoue Y., Watanabe T., Watanabe T.K., 1984. Evolutionary change of the chromosomal polymorphism in Drosophila melanogaster populations. Evolution, 38, 753-765.

Jones J.S., Yamazaki T., 1974. Genetic background and the fitness of allozymes. Genetics, 78, 1185-1189.

Lindsley D.L., Grell E.H., 1972. Genetic variation of Drosophila melanogaster. Carnegie Inst. Washington Publ., 627.

McKenzie J.A., Parsons P.A., 1972. Alcohol tolerance: an ecological parameter in the relative success of D. melanogaster and D. simulans. Oecologia, 10, 323-388.

McKenzie J.A., Parsons P.A., 1974. Microdifferentiation in a natural population of $D$. melanogaster to alcohol in the environment. Genetics, 77, 385-394. 
Mettler L.E., Voelker R.A., Mukai T., 1977. Inversion clines in populations of $D$. melanogaster. Genetics, 87, 169-176.

MoRgan P., 1975. Selection acting directly on an enzyme polymorphism. Heredity, 34, 124-127.

Mukai T., Mettler L.E., Chigusa S.I., 1971. Linkage disequilibrium in a local population of Drosophila melanogaster. Proc. Natl. Acad. Sci. U.S., 68, 1065-1069.

NÁJERA C., 1985. Variabilidad de mutaciones que afectan al color de los ojos en poblaciones naturales y experimentales de D. melanogaster. Tesis Doctoral, Universidad de Valencia.

NÁsera C., MÉnSUA J.L., 1985. Effect of alcohol and competition levels on viability of eye colour mutants of Drosophila melanogaster. Génét. Sél. Evol., 17, 331-340.

OAKESHOtт J.G., 1976. Selection at the alcohol dehydrogenase locus in Drosophila melanogaster imposed by environmental ethanol. Genet. Res., 26, 265-274.

OAKESHOTT J.G., 1979. Selection affecting enzyme polymorphism in laboratory populations of Drosophila melanogaster. Oecologia, 43, 341-354.

OAKEShotT J.G., GiBson J.B., 1981. Is there selection by environmental ethanol on the alcohol dehydrogenase locus in Drosophila melanogaster? In : Genetic studies of Drosophila populations, 103-120. Aust. Nat. Univ. Press, Canberra.

Van Delden W., Boerema A.C., Kamping A., 1978. The Adh polymorphism in populations of D. melanogaster. I. Selection in different environments Genetics, 90, 161-191.

Van Herrewege J., David J.R., 1984. Extension of life duration by dietary ethanol in Drosophila melanogaster : response to selection in two strains of different origins. Genetica, 63, 61-70.

Voelker R.A., Cockerham C.C., Johnson F.M., Schaffer H.E., Mukai T., Mettler L.E., 1978. Inversions fail to account for allozyme clines. Genetics, 88, 515-527. 